\title{
DESCENTRALIZAÇÃO E PODER LOCAL EM ALEXIS DE TOCQUEVILLE ${ }^{1}$
}

\author{
Klaus Frey \\ Pontifícia Universidade Católica do Paraná
}

\begin{abstract}
RESUMO
A partir da apresentação de alguns elementos básicos do pensamento de Alexis de Tocqueville - sua concepção de uma democracia liberal, seu conceito de liberdade e a sua teoria do interesse bem compreendido - analisamos neste artigo a concepção tocquevilleana sobre descentralização e poder local sobretudo no que diz respeito à sua contribuição para as teorias democráticas contemporâneas e para a fundamentação teórica de uma abordagem democratizante da descentralização político-administrativa.
\end{abstract}

PALAVRAS-CHAVE: poder local; descentralização; Tocqueville; teoria da democracia

\section{INTRODUÇÃO}

Buscamos neste trabalho analisar a concepção tocquevilleana sobre descentralização e poder local. Partimos da convicção de que a (re)leitura dos clássicos do pensamento político cabe não somente enquanto objetivo em si mesmo, não somente pela possibilidade de que o conhecimento do modo de pensar de nossos antepassados possa contribuir para entender melhor os fundamentos de nosso atual estado de consciência e para alcançar um conhecimento mais profundo do nosso próprio tempo, mas também porque supomos que existem problemas e fenômenos que ocorrem reiteradamente na convivência dos homens em sociedade, e que têm relevância universal para a vida social e sobre os quais autores de tempos remotos fizeram afirmações importantes. Isso, sem dúvida, vale para o pensamento de Alexis de Tocqueville, justificando portanto uma leitura de sua obra com o mesmo intuito com o qual o próprio Tocqueville realizou seu estudo sobre a sociedade americana, a saber, a busca pragmática por "ensinamentos dos quais pudéssemos tirar proveito" (TOCQUEVILLE, 1977, p. 19).

\footnotetext{
1 Este artigo baseia-se em uma pesquisa sobre "Desenvolvimento sustentável, democracia e gestão municipal: fundamentos teórico-conceituais para um modelo democratizante de gestão ambiental para municípios”, financiada pelo CNPq.
}

No que diz respeito à reflexão teórica acerca do poder local, notam-se déficits referentes à inclusão da dimensão "poder local" na teoria do Estado moderno, particularmente por parte da Ciência Política. Enquanto ainda para Aristóteles o enfoque central era a cidade, ou seja, a comunidade política que "visa ao mais importante de todos os bens" (ARISTÓTELES, 1997, p. 13), onde o homem enquanto animal social pode chegar ao auge de seu desenvolvimento e, deste modo, participar de uma vida melhor; com o surgimento do Estado moderno e a diversificação e complexificação da sociedade moderna, o poder local perde seu devido lugar nas concepções teóricas sobre o Estado e a democracia. Nunes chega até a falar de um "não lugar das unidades subnacionais, em particular do município ou comuna, no pensamento político moderno" (NUNES, 1996, p. 32).

Essa afirmação, no entanto, parece-me um pouco equivocada face, por exemplo, à utopia rousseauniana de um contrato social baseado na igualdade e na liberdade, que - inspirada pela democracia vivida por ele na cidade de Genebra pressupõe a unidade pequena, uma comunidade homogênea com uma diversidade limitada de interesses, como também face à asserção de Tocqueville de que a liberdade se efetiva mais facilmente em pequenas nações onde as fortunas costumam ser mais moderadas, os costumes mais simples e tranquiilos e onde o amor pelo país costuma ser mais intenso: "To choose liberty 
means to choose a simple life, and the true home of such a life is the small republic" (ALULIS, 1998, p. 87).

Com Alexis de Tocqueville surge, quase um século depois de Rousseau e da Revolução Francesa, um autor tal como Rousseau, movido pela inquietação pela liberdade, mas não mais se atendo ao ideal democrático da pólis e contemplando os condicionantes da liberdade política no contexto da sociedade moderna de massa.

Analisamos neste artigo alguns conceitos teóricos básicos da obra de Tocqueville - sua concepção de uma democracia liberal, seu conceito de liberdade e a sua teoria do interesse bem compreendido -, os quais visam o estabelecimento de uma ordem social baseada e sustentada por uma nova cultura política da liberdade, impulsionada pela própria sociedade civil. Tais elementos da teoria política de Tocqueville são fundamentais para suas concepções de poder local e descentralização, as quais serão apresentadas na seqüência. Nas considerações finais será enfatizada a importância do pensamento tocquevilleano para o atual debate em torno das teorias da democracia.

\section{ELEMENTOS BÁSICOS DO PENSAMENTO TOCQUEVILLEANO PARA SUBSIDIAR UMA TEORIA DO PODER LOCAL E DA DESCENTRALIZAÇÃO}

Como Jean-Jacques Rousseau, também Alexis de Tocqueville vê com bastante desconfiança a consolidação da sociedade pequeno-burguesa caracterizada pela predominância da atividade comercial e industrial, mas não por ater-se ou identificar-se - como Rousseau - com a simplicidade e autenticidade da vida natural de comunidades tradicionais de caráter rural, mas, ao contrário, por temer a perda da grandeza, da glória e da liberdade que o ancien régime ofereceu e proporcionou, pelo menos aos integrantes da aristocracia dirigente. "Descendente de uma grande família, Tocqueville oscila, nos seus julgamentos a respeito da sociedade democrática, entre a severidade e a indulgência, entre uma reticência do seu coração e uma adesão hesitante da sua razão" (ARON, 1993, p. 210) ${ }^{2}$.

2 "I have an intellectual taste for democratic institutions, but I am an aristocrat by instinct, which means that I scorn and fear the crowd” (BOESCHE, 1987, p. 169). Essa citação,
Na sua interpretação do processo históricosocial, Alexis de Tocqueville parte da tese da "inevitabilidade histórica da democracia" (JASMIN, 1997b, p. 202). O igualitarismo estaria em vias de se consolidar e de se generalizar, sem que para isso fossem necessários maiores esforços por parte dos atores políticos. O gradual desenvolvimento da igualdade enquanto "fato consumado" (TOCQUEVILLE, 1977, p. 19) ou "realidade providencial" (idem, p. 13) 3 assume função fundamental tanto para a historiografia como para a teoria política de Tocqueville. No entanto, enquanto ainda para Rousseau a condição de igualdade representava um objetivo indubitavelmente positivo e desejável, em Tocqueville a força irresistível do igualitarismo e da democratização inspira "um terror religioso" (Georges Lefebvre, apud JASMIN, 1997b, p. 203), ao colocar em risco a liberdade e preparar o caminho para a servidão ou o despotismo. É a igualdade, e não a liberdade, o aspecto fundamental que caracteriza a democracia, à qual o liberalismo é condenado a se abrir, a fim de poder preservar e garantir a liberdade para a época da igualdade (DÖHN, 1998, p. 218). Uma vez declarado o crescente igualitarismo como condição social vitoriosa restam, para Tocqueville, somente duas possíveis alternativas: ou a liberdade democrática ou o despotismo democrático (ZETTERBAUM, 1967, p. 3). A sua expectativa era pessimista. Tocqueville previu a difusão do individualismo moderno, que conduziria ao isolamento social dos homens e a atitudes alheias à virtude cívica e ao engajamento público, devido ao economicismo e ao consumismo que vêm acompanhando o crescente bem-estar privado usufruído pela grande massa da população. O resultado seria um despotismo moderno "que escraviza as almas sem atormentar os

extraída de um fragmento não publicado, evidencia o dilema e a tensão vividos por Tocqueville.

3 A discussão em torno de como interpretar a questão da Providência na obra de Tocqueville é bastante controversa; ver a respeito JASMIN (1997a; e 1997b). Importante para nossa análise é o fato de Tocqueville não questionar o crescente igualitarismo que é considerado uma ameaça à liberdade. $\mathrm{Na}$ interpretação de VIANNA (1993), Tocqueville conscientemente se nega a explicar a Providência para não perder de vista seu objetivo principal, que é, acima de tudo, encontrar na análise do processo de socialização e no estudo das mudanças sociais respostas sobre como preservar a liberdade num contexto de crescente democratização (p. 165s). 
corpos" (BORON, 1994, p. 148).

O "drama teórico tocquevilleano" (QUIRINO, 1998, p. 248) consiste na esperança por ele depositada na ação política de homens dotados de espírito cívico, perseguindo o ideal de liberdade. Essa esperança opõe-se à sua análise pessimista e fatalista do processo histórico ${ }^{4}$, que é conseqüência de sua avaliação de que as condições sociais, econômicas e políticas são fatores determinantes e condicionantes da atividade pública. A preocupação primordial de Tocqueville é um suposto declínio da liberdade em consequiência do aumento do igualitarismo.

Apresentarei a seguir os três elementos básicos do pensamento tocquevilleano que me parecem centrais para subsidiar uma abordagem democratizante da descentralização político-administrativa, além de enriquecer os atuais debates teóricos e práticos - em torno das possibilidades de uma (re)vitalização das democracias contemporâneas.

Em primeiro lugar, convém frisar as semelhanças entre a imagem idílica rousseauniana da "época mais feliz e a mais duradoura", na qual a humanidade teria ocupado "uma posição média exata entre a indolência do estado primitivo e a atividade petulante de nosso amor-próprio" e onde o mundo teria vivido sua "verdadeira juventude" (ROUSSEAU, 1973b, p. 270; cf. também OLDFIELD, 1990, p. 116), e a utopia tocquevilleana da sociedade democrática, que não se tornou vítima do despotismo democrático: "Imagino, então, uma sociedade na qual todos, considerando a lei como obra sua, ter-lhe-iam amor e a ela se submeteriam de bom grado; uma sociedade na qual, por ser a autoridade do governo respeitada como algo necessário e não de natureza divina, o amor que se demonstraria ao chefe de Estado não seria jamais uma paixão, mas um sentimento racional e tranqüilo. Como todos teriam direitos e lhes seria assegurada a conservação de seus

\footnotetext{
4 No que se refere à inconsistência que caracteriza a tese tocque-villeano da inevitabilidade, compare-se também com Zetterbaum (1967, p. 12ss). Hannah Arendt até fala no desespero que, em conseqüência da sua análise histórica, teria acometido Tocqueville em relação ao futuro da liberdade da ação política, lembrando-se da asserção tocquevilleana de que "desde [que] o passado deixou de lançar sua luz sobre o futuro a mente do homem vagueia na escuridão" (ARENDT, 1997, p. 111ss).
}

direitos, estabelecer-se-ia entre todas as classes uma confiança viril e uma espécie de recíproca condescendência, tão distante do orgulho quanto da humildade servil" (TOCQUEVILLE, 1977, p. $15 \mathrm{ss})$.

Tocqueville, em sua "utopia realista", de certo modo abre mão do suposto esplendor da liberdade como sendo própria do regime aristocrático, esboçando um modelo social que preserva o máximo de liberdade, dentro do que lhe parecia possível no contexto da progressiva democratização das condições sociais: "embora encontremos nesse Estado menos esplendor que no seio de uma aristocracia, também encontraremos menos misérias; os prazeres, dentro dele, serão menos extremos, e mais geral o bem-estar; as ciências, menos perfeitas, mas a ignorância, mais rara; os sentimentos, menos enérgicos, porém mais suaves os hábitos; encontrar-se-ão dentro dele mais vícios e menos crimes. [...] Tomada em conjunto, a nação há de ser menos brilhante, menos gloriosa, talvez até menos forte; dentro dela, porém, a maioria dos cidadãos gozará de uma sorte mais próspera, o povo mostrar-se-á pacífico, não por desesperança de vir a melhorar, mas por saber que já se acha bem" (TOCQUEVILLE, 1977, p. 16).

Em segundo lugar, é preciso destacar a ênfase ou paixão pela liberdade que figura como motivo norteador da reflexão teórica. Toda a obra de Tocqueville é entretecida com a seguinte preocupação permanente: "como seria possível adequar o que considerava fundamental para a existência de qualquer ser humano, a liberdade de cada um, tanto como indivíduo quanto como cidadão, à realidade sócio-política existente" (QUIRINO, 1998, p. 247)? Seu estudo sobre a democracia na América é motivado pela busca pragmática por "ensinamentos dos quais pudéssemos tirar proveito" (TOCQUEVILLE, 1977, p. 19), para poder salvaguardar a liberdade nos tempos de crescente igualdade, tendo ele como objetivo particular preparar a sociedade francesa, onde "o prestígio do poder real desvaneceu-se sem ser substituído pela majestade das leis" (idem, p. 16), para os tempos democráticos.

Em nítida contraposição à concepção rousseauniana, na qual a realização da liberdade é estreitamente vinculada à igualdade social e à efetivação da vontade geral, a liberdade para Tocqueville independe da condição social e 
corresponde basicamente a uma modalidade do agir político, esta própria dos espíritos mais elevados. $\mathrm{O}$ amor pela liberdade política representa o valor mais sublime na concepção política tocquevilleana, como ele salienta em $O$ Antigo Regime e a Revolução: "Muitas vezes cheguei a me perguntar onde estaria a fonte desta paixão pela liberdade política que, em todos os tempos, levou os homens a realizar as maiores coisas que a humanidade cumpriu e em que sentimentos está se enraizando e alimentando" (TOCQUEVILLE, 1982, p. 160).

Reivindicações de liberdade, no seu entender, freqüentemente não passam de críticas à ineficiência e à incapacidade de governantes opressivos ou a males passageiros produzidos por regimes despóticos: "pensavam amar a liberdade quando na realidade só odiavam o dono" (ibidem). Também descarta Tocqueville a possibilidade de que esperanças referentes a um bem-estar melhor ou ao aumento da igualdade poderiam fomentar o espírito da liberdade: "Tampouco creio que o verdadeiro amor da liberdade jamais tenha sido gerado pela única visão dos bens materiais que oferece, pois esta visão muitas vezes fica turvada [...]. Os povos que nela [na liberdade] só apreciam estes bens nunca a conservaram por muito tempo" (ibidem).

A liberdade só tem chances de perdurar quando compreendida como um bem em si mesmo: "O que, em todos os tempos, tão fortemente agarrou os corações de certos homens à liberdade é sua própria atração, seu encanto, independentemente de suas dádivas; é o prazer de poder falar, agir, respirar sem constrangimento sob o único Deus e de suas leis. Quem procura na liberdade outra coisa que ela própria foi feito para a servidão [...]. Não me peçam analisar um gosto sublime, que é preciso sentir. Entra por si mesmo nos grandes corações que Deus preparou para recebê-lo, enchendo-os e inflamando-os. Temos de renunciar a explicá-lo às almas medíocres que nunca o sentiram" (idem, p. 160ss).

Nessas únicas passagens em que Tocqueville pronuncia-se de maneira explícita sobre sua representação do conceito de liberdade, evidenciase a liberdade como um valor sobremaneira "aristocrático", "a grace granted to a few" (MANENT, 1998, p. 82), que, por se tratar de uma dádiva divina, só pode ser vivenciada, mas não ser sujeita a uma análise científica. Da maneira como Tocqueville exalta os "grandes corações" e trata com desdém as "almas medíocres", ele, de acordo com Manent, não deixa dúvida de que seu amor pela liberdade "has a foundation that is clearly and emphatically inegalitarian and thus antidemocratic" (idem). Considerando que Tocqueville associa o valor da liberdade às antigas instituições feudais e ao republicanismo puritano dos imigrantes fundadores das comunas americanas, a liberdade tocquevilleana não deixa de ser "filha da tradição" (VIANNA, 1993, p. 175). Sendo este amor pela liberdade associado à desigualdade, ele contradiz diretamente os fundamentos da democracia. É isso a base para a tensão permanente entre a liberdade e a democracia que tão enfaticamente está presente na obra tocquevilleana.

Mas Tocqueville não pode deixar de reconhecer que essa forma idílica e não democrática de liberdade, exaltado por ele, não corresponde ao tipo de liberdade que vem sendo exercida nas sociedades aristocráticas realmente existentes. $\mathrm{Na}$ sociedade moderna e complexa, caracterizada pelo aumento das chances sociais, a visão holística de uma sociedade harmoniosa e integrada, onde cada segmento da sociedade ocupa seu devido lugar de acordo com suas habilidades, capacidades e particularidades individuais, grupais, raciais, de estamento ou de classe ${ }^{5}$, se torna sempre menos convincente face às reivindicações sociais da população. Ficam sempre mais evidentes os privilégios e interesses particularistas embutidos e encobertos nestas representações ideológicas: "Aristocratic liberty is the "enjoyment of a privilege'; it is a noble version of 'egoism'; it is inseparable from a proud domination over those who are not free. Aristocratic liberty is not pure" (MANENT, 1998, p. 83).

Portanto, nem na democracia, nem na aristocracia existem condições para o desenvolvimento desse amor pela liberdade. Essa visão bastante cética referente à possibilidade da preservação - ou criação - da tão almejada liberdade política, porém, não o induz a abrir mão da sua

\footnotetext{
5 Essa concepção está presente em todo pensamento conservador, desde Aristóteles aos defensores da democracia elitista, como também nos reputados representantes do pensamento social brasileiro, como, por exemplo, em Gilberto Freyre, com sua concepção da democracia racial, imagem que se evidencia tão vantajosa e cômoda às aristocracias dominantes.
} 
busca, haja vista que a desistência equivale, no entender de Tocqueville, a uma decisão pelo caminho da servidão. Pelo contrário, a necessidade de um empenho incondicional a favor da liberdade impõe-se face às ameaças despóticas do igualitarismo que estão prestes a se instituir "quando o gosto pelos prazeres materiais se desenvolve num desses povos mais rapidamente que as luzes e os hábitos da liberdade" (TOCQUEVILLE, 1977, p. 412). Consiste exatamente nesta insistência de Tocqueville na realização da liberdade enquanto valor intrínseco, uma das suas contribuições mais importantes e originais para o liberalismo, cujos fundadores enfocaram muito mais a liberdade enquanto um meio e um efeito, e muito menos enquanto um valor que deve ser buscado em si mesmo.

O terceiro ponto que deve ser levantado referese à importância atribuída ao interesse individual na concepção democrática de Tocqueville. Em todo pensamento liberal o argumento utilitarista está presente. Até Rousseau, com sua glorificação da coletividade (expressa na sua teoria radical de soberania popular e na sua insistência na idéia da vontade geral), não consegue dispensar de recorrer a um "certo individualismo paradoxal e pragmático" (SOUZA, 1988, p. 64) para justificar sua tese da proficuidade da subordinação à vontade geral e sua busca por "alguma regra de administração legítima e segura”. Como ele afirma já no parágrafo inicial de $O$ contrato social: "Esforçarme-ei sempre, nessa procura, para unir o que o direito permite ao que o interesse prescreve, a fim de que não fiquem separadas a justiça e a utilidade" (ROUSSEAU, 1973a, p. 27).

Tocqueville, em contrapartida, reconhece a diversidade de interesses, mas não aceita as soluções contratualistas, que de certo modo sacrificam a liberdade individual em nome da pacificação dos conflitos de interesses por meio de um Estado sobreposto à sociedade. A chave para a arbitragem de conflitos de interesses Tocqueville não busca em uma força externa - no Estado -, mas sim dentro da própria sociedade. É a virtude que deve ser fomentada para as sociedades poderem chegar a alcançar a liberdade, o que na sociedade mercantil-burguesa só será possível se os cidadãos passarem a identificar o exercício da liberdade política na esfera pública com seus próprios interesses privados. O problema que se coloca para Tocqueville é "como enfrentar essa cisão [entre as esferas pública e privada], longe das tentações holísticas de submissão do indivíduo e do seu interesse a um Estado que encarne a vontade geral da sociedade" (VIANNA, 1993, p. 169ss).

Tocqueville, diante deste dilema, opta pela conciliação das duas esferas, que só pode ser alcançada por meio de uma prática social educadora que leva à transformação do egoísmo em um "interesse bem compreendido". Inspirando-se na experiência americana, Tocqueville conclui que só pode se esperar um envolvimento maior por parte da população na vida política no caso de a prática pública integrar-se ao mundo dos interesses privados. Na busca por um fundamento em comum da ordem social, Tocqueville não aposta nos interesses que as pessoas têm em comum - tais interesses a longo prazo não seriam suficientes; além do mais, em certas circunstâncias esses interesses poderiam até separar as pessoas. Ele mostra-se preocupado com o estabelecimento de uma ordem que seja firmemente ancorada no pensar, no agir e nos costumes dos cidadãos. $\mathrm{O}$ único bem que teria um potencial de unir os indivíduos e determinar o pensar, o agir e o comportamento dos cidadãos seria a liberdade (HERETH, 1979, p. 20). Ela manifesta-se na prática do exercício da cidadania, a única maneira possível de garantir a superação do predomínio do auto-interesse, no sentido mais estreito, e a sua substituição pelo interesse bem compreendido, abrindo possibilidades para uma prática de perseguição do bem-estar público na sociedade. $\mathrm{Na}$ América, o alto grau de participação na vida política fez que "the citizen was prepared to sacrifice immediate private interest in order to preserve the hole of which he was a part" (OLDFIELD, 1990, p. 140). O governo democrático desempenhou o papel de educador, contribuindo para a ampliação dos horizontes mentais, para o esclarecimento e um envolvimento mais criativo do povo nas questões públicas (idem, p. 129-134).

Acontece que nas sociedades onde o gosto pela liberdade não consegue acompanhar os avanços do igualitarismo, os homens, "preocupados apenas com o cuidado de fazer fortuna, não percebem o estreito laço que une a fortuna particular de cada um deles à prosperidade de todos" (TOCQUEVILLE, 1973, p. 412). O desprezo dos homens pelo interesse supremo - "continuar senhores de si mesmos" (idem, p. 413) - deve-se a uma 
perturbação da capacidade de percepção causada pelo consumismo, o conformismo e o imediatismo predominantes nas sociedades igualitárias, que logo bloqueia a ação política e o engajamento público: "Os homens que têm a paixão pelos gostos materiais descobrem, via de regra, como as agitações da liberdade perturbam o bem-estar, antes de perceber como a liberdade serve para proporcionálo" (ibidem).

A fim de garantir a boa ordem, condição considerada fundamental para o usufruto desenfreado do bem-estar material, os homens tornamse prestes a "atirar fora a liberdade" (ibidem), abrindo o caminho para a tirania: "Uma nação que não pede ao seu governo senão a manutenção da ordem é já escrava, no fundo do coração; é escrava do seu bem-estar e está prestes a surgir o homem que deve prendê-la com correntes" (ibidem).

Nos Estados Unidos, no entanto, apesar de os prazeres materiais dos americanos parecerem-lhe particularmente violentos, a paixão pelos prazeres materiais pelo menos não equivaleria a uma paixão cega, por ser dirigida pela razão, na medida em que o amor pelo bem-estar une-se e finalmente até se confunde com o amor pela liberdade. "Os americanos, na verdade, vêem na sua liberdade o melhor instrumento e a melhor garantia de seu bem-estar. Amam essas duas coisas, uma pela outra" (idem, p. 414).

Essa concepção utópica de uma democracia capaz de reconciliar a liberdade com a igualdade, assegurada pelo predomínio do interesse bem compreendido no processo político, pressupõe a vigência de uma correspondente cultura política, impulsionada por uma nova prática de ação política e social dentro da própria sociedade civil.

Enquanto nos Estados Unidos a liberdade é imanente ao processo específico de seu desenvolvimento histórico, encontrando-se portanto presente nas suas instituições, nos costumes e suas práticas políticas e sociais, de maneira incontestada, nos países desiguais do velho continente não é possível dispensar um processo educador, sustentado por uma nova sociabilidade, fomentada pela própria Ciência Política. Porém, os princípios e exigências desse processo educador não podem simplesmente ser determinados por uma razão abstrata, o que significa que o "esclarecimento" dos interesses particularistas não pode efetivar-se através do Estado, através de novas leis e insti- tuições instituídas por um Estado esclarecido. A prática do associativismo americano, tão essencial para a garantia da liberdade política (OLDFIELD, 1990, p. 120), não foi e não poderia ter sido implementado por decreto presidencial, mas é resultado de uma "necessidade contínua de associação", presente nesta sociedade democrática e liberal: "a grande liberdade política aperfeiçoava e vulgarizava em seu seio a arte de se associar" (TOCQUEVILLE, 1973, p. 412).

Para Tocqueville, contudo, as instituições têm uma importância apenas relativa: "Não existe nada de absoluto no valor teórico das instituições e sua efetividade quase sempre depende das condições originais do estado social do povo, no qual foram aplicadas" (Tocqueville, em uma carta para seu pai, 3.jun.1831, apud HERETH, 1979, p. 20).

As instituições teriam só "uma influência secundária no destino dos homens", o que fundamenta sua falta de esperança no futuro e na possibilidade de uma (re)engenharia institucional poder proporcionar a liberdade: "Teria mais esperança no futuro, porque por acaso poderíamos algum dia topar com um precioso pedaço de papel que contivesse a receita para todos os males, ou com o homem que conhecesse a receita. Mas infelizmente tal coisa não existe e eu estou bastante convencido de que as sociedades políticas não são o que suas leis fazem delas, mas o que os sentimentos, as crenças, as idéias, os hábitos do coração e o espírito dos homens que as formaram, as prepararam com antecedência para ser, assim como o que a natureza e a educação fizeram delas" (Tocqueville, em uma carta a um amigo, apud DIGGENS, 1999, p. 31).

O surgimento de um novo padrão de ação social capaz de garantir a liberdade e sintonizado com as características de uma sociedade crescentemente igualitária exige a transformação paulatina dos costumes e tradições dentro da própria sociedade civil6; nesta concepção, "a democracia se define a partir da sociedade civil" (BORON, 1994, p. 128). Como lembra Döhn, "Tocqueville demonstra aos europeus continentais que liberdade e democracia não são resultado de constituições,

\footnotetext{
6 Nesse sentido, a posição de Tocqueville se contrapõe à visão idealizadora do Estado em Hegel; ver a respeito Vianna, (1993, p. 169-173).
} 
por mais indispensáveis que estas sejam, mas que elas têm que ser integradas na sociedade como conse-qüência das condições históricas e societais" (DÖHN, 1998, p. 189).

Tocqueville compartilha com John Stuart Mill uma postura cética frente ao liberalismo constitucional que se limita a precauções institucionais para a garantia da liberdade 7 . É próprio do liberalismo enquanto teoria da dominação burguesa abstrair a realidade social e, ao mesmo tempo, omiti-la, o que, de acordo com Döhn, representa uma das fraquezas fundamentais de todo o liberalismo. Tanto Mill como Tocqueville, contrapondo-se a essa concepção formalista do liberalismo constitucional, tematizam a compatibilidade das precondições reais da dominação social com os teoremas básicos da liberdade, igualdade e da soberania popular. Ambos autores, o primeiro salientando as restrições sócio-econômicos, o segundo a centralidade da questão dos hábitos e valores morais, chegam a exigir a ampliação da participação política e uma politização do processo político. O exercício empírico da liberdade política deve ser enxergado como um processo de aprendizagem, imprescindível para que os homens possam passar a valorizar a liberdade sem dela abusar (DÖHN, 1998, p. 190).

Face às preocupações centrais de Tocqueville - o declínio da virtude cívica em razão do crescente individualismo, materialismo e consumismo da sociedade moderna, a que se soma o risco de perda da liberdade, da autodeterminação e da dignidade humana, e, finalmente, o reconhecimento de que os valores fundantes de uma ordem democrática têm que se basear nos interesses individuais -, fica bastante evidente a busca e exigência de um corpo político-social apoiado em laços fortes de solidariedade, os quais só podem ser alcançados por uma prática de ampla participação da população no processo político - por sinal, uma visão que Tocqueville tem em comum com o próprio Rousseau. Apesar do ceticismo que os dois autores compartilham referentemente à probabilidade de se chegar à liberdade ${ }^{8}$, o processo

\footnotetext{
7 Disso provém sua crença na insuficiência e ineficácia dos dispositivos constitucionais elaborados pelos formuladores da Constituição americana para proteger ou promover a liberdade; ver também Diggens, (1999, p. 31).

8 Boron fala, no caso de Tocqueville, de um "pessimismo esperançoso" acerca do futuro da democracia (1994, p. 127).
}

participativo é considerado por ambos como fundamental para manter abertas as chances de, respectivamente, criar ou salvaguardar a liberdade e alcançar o bem comum.

Contudo, Rousseau não consegue transpor seu horizonte empírico pequeno-burguês e não consegue abrir mão da sua representação idílica de uma sociedade simples e arcaica. Desconsiderando as condições reais da sociedade da sua época, encontrando-se esta num profundo processo de transformação, Rousseau perde a possibilidade de pensar seu modelo da soberania popular e da vontade geral - teoricamente consistente e coerente $^{9}$ mas empiricamente insustentável - para a realidade complexa das sociedades modernas. Tocqueville, ao contrário, norteando-se e inspirando-se nas experiências empíricas e mostrando uma sensibilidade muito grande referentemente às transformações sociais em curso naquela época, tanto na América quanto no velho continente, esforça-se explícita e declaradamente - ainda que de maneira relutante - em deixar para trás seus laços e sua simpatia para com o ancien régime, buscando salvar o que de mais valioso, de acordo com seu juízo, esta ordem antiga representa: a liberdade política.

Este pragmatismo e perspicácia faz Tocqueville avançar no sentido de pensar uma concepção moderna e liberal de democracia, fazendo dele, de acordo com DÖHN (1998, p. 217), o primeiro teórico liberal que demonstra empiricamente a possível vitalidade de Estados democráticos de grande porte. Porém, essa vitalidade é ameaçada constantemente pelo avanço do igualitarismo, por apresentar uma tendência sufocadora da liberdade, pois há risco de se instituir uma "tirania da maioria". Esse conceito, na compreensão tocquevilleana, refere-se não somente aos efeitos do princípio da maioria no processo de decisão política, mas abrange também a idéia de uma tirania uniformizadora que se estenderia à vida psicossocial, intelectual e cultural, suprimindo a diversidade social. As respectivas idéias e sentimentos democráticos, por sua vez, influenciam o funcionamento e as características da sociedade política ${ }^{10}$.

\footnotetext{
9 Hannah Arendt considera Rousseau "o representante mais coerente da teoria da soberania” (ARENDT, 1997, p. 211).

10 Ver, sobre os efeitos do igualitarismo para as idéias, sentimentos e costumes, as partes I, II e III do segundo livro
} 
No seu estudo clássico sobre a transformação estrutural da esfera pública, Jürgen Habermas salienta que tanto para Alexis de Tocqueville como para John Stuart Mill o processo da crescente democratização leva à uniformização da opinião pública e à deterioração da esfera pública. Esta "permeia sempre mais esferas da sociedade e perde ao mesmo tempo sua função política, a saber, submeter os fatos publicados ao controle de um público crítico" (HABERMAS, 1962, p. 171).

Portanto, a opinião pública, determinada pelas paixões das massas, requer uma limpeza por meio do juízo abalizado de cidadãos materialmente independentes. A opinião pública, na teoria burguesa do Estado de Direito, ainda concebida enquanto instrumento de libertação, é considerada, na teoria liberal, como uma instância de opressão, o que exige a introdução de elementos restritivos na concepção de esfera pública, "a fim de assegurar a uma opinião pública que se tornou minoritário - e contra as opiniões dominantes - a influência que ela não consegue mais exercer por si mesma" (idem, p. 167).

Por outro lado, enquanto Mill se conforma com a psicologia social do público de massa e exige uma esfera pública hierarquizada e meramente representativa, Tocqueville identifica - ao lado da tirania da opinião pública - uma outra tendência que ameaça a autonomia do cidadão: a centralização do poder governamental e, conseqüentemente, o despotismo devido à crescente burocratização do Estado (idem, p. 168). É a partir dessa análise que Tocqueville desenvolve suas concepções de descentralização e poder local, que trazem elementos importantes visando à reconquista da autonomia da ação política pelo cidadão e à vitalização da vida política e pública.

\section{CENTRALIZAÇÃO E DESCENTRALI- ZAÇÃO}

Tocqueville, nos seus escritos, valoriza sobremaneira a pequena comunidade política, pois só esta pode proporcionar a solidariedade indispensável para a estimulação da virtude cívica e para a preservação da liberdade política. Além disso, ele

de $A$ democracia na América. A influência das idéias e dos sentimentos democráticos sobre a sociedade política são expostas por Tocqueville na quarta parte do segundo livro da mesma obra. atribui ao engajamento do cidadão em nível local valor fundamental não apenas para a democracia local em si, mas também para dar sustentação à democracia no nível nacional. Todavia, Tocqueville não se atém mais ao ideal clássico da pólis como Rousseau, reconhecendo a necessidade de uma estrutura federal para viabilizar a democracia na sociedade de massa (WASCHKUHN, 1998, p. 229).

Um primeiro aspecto importante na concepção tocquevilleana é sua afirmação de que "a centralização será o governo natural" dos povos democráticos. Os sentimentos e os hábitos dos povos democráticos seriam favoráveis à concentração de poder. A inexistência de hierarquias e de relações de subordinação nas sociedades igualitárias faz com que as pessoas, impulsionadas por "uma força secreta", volvam-se sempre mais para si mesmas. O conseqüente fortalecimento do individualismo proporciona a despolitização da vida pública nas sociedades modernas: "A vida privada é tão ativa nos tempos democráticos, tão agitada, tão cheia de desejos, de trabalhos, que quase não resta mais energia nem vagar a cada homem para a vida política" (TOCQUEVILLE, 1977, p. 515).

O problema da falta de ócio para poder se dedicar à coisa pública - para Aristóteles, o argumento central para excluir dos cargos públicos todas aqueles que estão engajados na luta diária pela sobrevivência - não se restringe mais apenas às camadas mais pobres, mas se transforma num elemento estrutural das sociedades democráticas e capitalistas, conseqüência de seu próprio êxito material, colocando em risco o dinamismo da vida pública.

Devido à preocupação primária pelo bem-estar privado e devido à volubilidade da propriedade, "o amor à tranqüilidade pública é, não raro, a única paixão política conservada por esses povos, e se torna entre eles mais ativa e mais poderosa, à medida em que todas as outras se apagam e morrem; isso dispõe naturalmente os cidadãos a constantemente abrir mão de novos direitos ou a deixar que os tome o poder central, que lhes parece ter, exclusivamente, interesse e meios para defendêlo da anarquia, defendendo-se a si mesmo" (ibidem).

Porém, o amor pelo poder central, importante lembrar, pressupõe tempos de igualdade: "Os homens que vivem nos séculos de igualdade amam naturalmente o poder central e de bom grado 
aumentam os seus privilégios; mas, se ocorre que esse mesmo poder representa fielmente os seus interesses e reproduz exatamente os seus instintos, a confiança que nele têm quase não conhece limites, e acreditam estar atribuindo a si mesmos tudo aquilo que a ele entregam" (idem, p. 520).

Do mesmo modo que a igualdade promove a concentração do poder, o poder centralizado mostra-se atento à realização da igualdade. Enquanto em sociedades desiguais - podemos pensar no caso brasileiro - "nenhuma desigualdade é tão grande que chegue a chamar atenção [...], a menor dessemelhança parece chocante no seio da uniformidade geral; a sua visão torna-se mais insuportável à medida que a uniformidade é mais completa. É natural, pois, que o amor à igualdade cresça constantemente com a própria igualdade; ao satisfazê-la, nós a desenvolvemos" (idem, p. 516). Além disso, o próprio poder central é crescentemente interessado na igualdade e na uniformidade, "pois a igualdade facilita, estende e assegura, singularmente, a ação de semelhante poder", e "a uniformidade poupa-lhe o exame de uma infinidade de detalhes com os quais se deveria ocupar, se fosse preciso fazer a regra para os homens, em lugar de submeter indistintamente todos os homens à mesma regra. Assim, o governo ama o que amam os cidadãos, e odeia naturalmente o que eles odeiam" (ibidem). A conseqüência é a centralização e burocratização da vida pública e da estrutura do Estado: "Tocqueville knew [...] that when men turned to the state to enlarge democracy and enhance justice, they inevitably strengthened the centralized government and brought into being a giant bureaucracy" (COMMAGER, 1993, p. 32).

O objetivo da igualdade é estreitamente relacionado com "a idéia de um governo único, uniforme e forte" (TOCQUEVILLE, 1977, p. 517) uma noção que se opõe claramente aos objetivos que orientam as concepções de descentralização ${ }^{11}$.

11 A centralização político-administrativa acarreta, por sua vez, um "desmedido crescimento da burocracia” (BORON, 1994, p. 136), uma preocupação de Tocqueville compartilhada por Max Weber. Mas ao passo que Weber dedica-se ao papel das instituições e organizações enquanto meios de dominação que podem fugir ao controle das vontades e intenções humanas (na medida em que estes meios podem transformarse nos próprios fins, perdendo com isso sua finalidade original), Tocqueville, na verdade, como já mencionamos
Como então salvar a liberdade cidadã da tirania da maioria e de um Estado crescentemente centralizado e burocratizado? De acordo com Boron, "a plena realização da liberdade - isto é, da democracia política - só é possível em uma formação social na qual tenham sido abolidas as relações sociais de exploração entre os homens" (BORON, 1994, p. 146). A crítica de Boron, de que o discurso tocquevilleano deixaria faltar os elementos imprescindíveis para tal compreensão, não me parece oportuna, visto que Tocqueville em nenhum momento alimentou esperanças, ou não se entregou à ilusão, de que tal "plena realização" da liberdade poderia ser alcançada na sociedade moderna. Essa suposta falta de perspicácia em relação à penetração da democracia política qualificação que Boron reserva exclusivamente ao "gênio Marx" (idem) - explica-se facilmente se verificarmos a essência da Ciência Política tocquevilleana - que consiste em uma intencionalidade bastante prática. Tocqueville pretende identificar as tendências do desenvolvimento social para dessa maneira fornecer subsídios para a orientação da ação política. Waschkuhn qualifica a Ciência Política tocquevilleana de "ciência de orientação construtiva" (1998, p. 230). Todo trabalho teórico-científico se dá em função da política prática e é orientado para a política. Contudo, uma compreensão mais adequada de sua idéia de liberdade não pode ser extraída de uma mera análise teórica, mas tem de incluir necessariamente o seu próprio modo de viver, direcionado para a política (HERETH, 1979, p. 24ss; RODRÍGUEZ, 1998, cap. 3).

As convicções e afirmações absolutas presentes em toda obra marxiana, sua visão determinista do processo histórico, dotado de sentido imanente, opõem-se tanto à visão weberiana quanto à tocquevilleana, nas quais, respectivamente, a "jaula de ferro" (em conse-

anteriormente, não mostra grande interesse pelas instituições como tais, sendo estas, no seu entender, mera conseqüência da cultura e prática política. Compartilhando em princípio os mesmos valores, os pontos de partida de suas preocupações eram distintas; para Weber era o processo da crescente racionalização que podia potencialmente desembocar em uma "jaula de ferro"; para Tocqueville era o igualitarismo que ameaçava levar a um despotismo moderno (idem, p. 147). "Weber procurou salvar da burocracia a liberdade e a moral; Tocqueville procurou salvar esses mesmos valores, mas da democracia” (DIGGENS, 1999, p. 32). 
qüência do processo de racionalização) e o "despotismo democrático" (em consequiência do processo de nivelamento social), devem ser compreendidas como representações idealizadoras no sentido dos tipos ideais weberianos - de um futuro estado social que, para ambos, ameaça a sobrevivência da liberdade. Mas ambos não descartam - apesar do inegável pessimismo presente neles - a possibilidade de a liberdade poder ser preservada no campo político: ou por meio de uma "democracia plebiscitária" enquanto contrapoder capaz de enfrentar a poderosa burocracia (Weber), ou por meio do exercício ativo da cidadania política via participação política, para despertar na população o gosto pela liberdade e fomentar a virtude cívica (Tocqueville).

A liberdade política, para Tocqueville, era um valor em si, o valor supremo que sempre deve ser almejado e buscado; mas ele não deixou dúvidas a respeito da ameaça a qual essa liberdade estaria permanentemente exposta nos tempos da igualdade. Logo, a busca pela liberdade será uma tarefa infinita, um processo que certamente nunca chegará ao seu fim. Uma vez que os homens dos tempos democráticos estão "sempre prontos a atirar fora a liberdade, à primeira desordem" (TOCQUEVILLE, 1977, p. 413) que possa ameaçar o usufruto irrestrito dos prazeres materiais, é indiscutível que a conservação da liberdade exige empenho e esforços ininterruptos e redobrados por parte de todos os cidadãos, aquela "energia irrequieta" (DIGGENS, 1999, p. 29) que Tocqueville alegou ter identificada no povo americano.

Qualquer estratégia que vise a manter vital essa inquietação e este zelo permanente pela conservação da liberdade precisa prever "uma recuperação plena da política, a reativação da cidadania, a reanimação da vida pública" (BORON, 1994, p. 148). Mas como proporcionar a vitalização da política? Na América Tocqueville detectou o júri popular, os partidos políticos e outras associações políticas e sociais, assim como o autogoverno local nos townships como instituições fundamentais para garantir uma vida política ativa e vital. Contudo, a descentralização é conditio sine qua non para a vitalização da democracia política, mas não garante por si que a liberdade política acabe saindo vitoriosa.

\section{O PODER LOCAL: ESCOLA PRIMÁRIA DA DEMOCRACIA}

Trata-se no caso das instituições fundamentais de esferas de ação social nas quais o cidadão americano pode livremente exercer sua cidadania, aprender a arte da política e pegar o gosto pela liberdade política. Comparando com as condições na França de sua época, onde todas as instituições intermediárias foram destruídas pelo furor da revolução, Tocqueville chega a reconhecer o valor fundamental de tais instituições para a consolidação de uma república verdadeiramente democrática. Na França, todas as responsabilidades e competências dos antigos poderes locais foram se acumulando no poder central, "o qual se tornou herdeiro de todas as competências de decisão até então distribuídas em todo país" (HERETH, 1979, p. 32). Conseqüência dessa acumulação de responsabilidades era uma sobrecarga do governo central, que não conseguiu dar conta das múltiplas e contraditórias demandas vindas de todos os cantos do país.

De modo geral, na medida em que numa sociedade de massa e em um território vasto todas as atenções acabam se direcionando para um poder único, o sistema político perde estabilidade, fazendo que, particularmente em tempos de crise, o poder central transforme-se no inimigo geral da sociedade. Essa inimizade com o governo central, assim como expectativas desmedidas por parte da população, podem, segundo Tocqueville, ser considerados indícios de uma falta de responsabilidade generalizada que necessariamente se propaga em uma sociedade cujos membros não dispõem de possibilidades de autodeterminar e deliberar sobre os assuntos de seu próprio interesse. A crescente igualdade de condições conduz, irresistivelmente, à ampliação das administrações centrais, especialmente "se ela se estabelece num país cujos cidadãos nunca tiveram ou não têm mais o hábito de tomar juntamente seus assuntos nas próprias mãos além da difícil arte de fazer isto de forma bem-sucedida" (Tocqueville, em uma carta para seu amigo Beaumont, de 1854, apud HERETH, 1979, p. 33). Em um corpo político de um país de grande extensão territorial só poucas pessoas poderão ter acesso à esfera pública. Quanto mais uma comunidade política centraliza competências e direitos decisórios, tanto menor o número de cidadãos dispondo realmente de acesso à esfera pública.

Enquanto na França os revolucionários de 1789 - introduzindo na Constituição de 1791 uma descentralização radical do poder e um deslocamento de competências para os níveis regional e 
local - tinham ainda clareza da importância da participação política em poderes intermediários e no nível local, a vida curta dessa descentralização, de acordo com Tocqueville, era responsável pelo fato de que os franceses nem chegaram a conhecer essa forma prática e ativa de liberdade política, condenando-se a conformar-se com uma ordem política que lhes propiciava a possibilidade de determinar o seu governante, mas lhes recusava uma participação efetiva nas decisões políticas, isto é, o autogoverno pelo povo (HERETH, 1979, p. 30ss). A participação nas eleições representativas é uma oportunidade muito importante do cidadão valer-se do uso do livre arbítrio, mas também é uma prática curta e rara e portanto insuficiente para impedir que os cidadãos "percam pouco a pouco a faculdade de pensar, de sentir e de agir por si mesmos, e que não venham a cair assim, gradualmente, abaixo do nível da humanidade" (TOCQUEVILLE, 1977, p. 533).

Contudo, a opção tocquevilleana pela valorização do poder local não se fundamenta na idéia de uma eficiência administrativa maior ou da uniformização territorial das condições de vida que hoje predomina na discussão em torno da descentralização. Ao contrário, numa carta ao seu amigo Beaumont, Tocqueville reconhece: "Quando o poder é repartido, a capacidade de ação é perceptivelmente dificultada"; porém, em compensação, ganha-se uma sociedade civil capaz de controlar os governantes, ou seja, "a resistência se encontra em todo lugar" (apud HERETH, 1979, p. 32). "A comuna era enxergada por Tocqueville como um foco de febril atividade social e de sadia emulação" (RODRÍGUEZ, 1998, p. 99).

Além disso, Tocqueville salienta a função das instituições políticas locais em ensinar ao cidadão o uso responsável da liberdade, em fazê-lo perceber a vantagem da liberdade (no sentido da teoria do interesse bem compreendido) e, finalmente, a sua contribuição para a promoção e o fortalecimento do - ainda que frágil - amor pela liberdade. Só quem experimentou a liberdade prática poderá desenvolver o gosto pela discussão e pela ação política e perceber a liberdade de ação como um valor almejável (HERETH, 1979, p. 28ss). "Decentralized political and economic participation push men and women from their private selfinterested worlds into the public, teach them in a practical way how to master their surroundings, remind them of their interdependence and of the pleasures of cooperation, and militate against the docility and sterility encouraged by centralization. Cooperative, decentralized efforts - efforts that release the latent potentials for popular energy and that impel men and women to master their political world - are the first mark of a free nation" (BOESCHE, 1987, p. 138).

$\mathrm{O}$ que Tocqueville tem em vista com a revitalização da democracia local não é apenas o fortalecimento da própria comunidade local, mas, como não menos importante, é sua contribuição para a maturação do "corpo eleitoral", indispensável para a consolidação da democracia no nível nacional: "Na verdade, é difícil imaginar como poderiam homens que renunciaram inteiramente ao hábito de se dirigir por si mesmos conseguir escolher bem aqueles que os devem conduzir; e nada fará acreditar que um governo liberal enérgico e sábio jamais possa sair do sufrágio de um povo de servos" (TOCQUEVILLE, 1977, p. 533) ${ }^{12}$.

Tocqueville parte do pressuposto de que as opiniões, o comportamento, as convicções e os hábitos são sujeitos a mudanças, podem ser cultivados ou podem pouco a pouco estiolar. As tão almejadas virtudes políticas só podem desenvolver-se na prática do agir político. Seria uma ilusão acreditar que o amor pela humanidade poderia impulsionar o engajamento cívico. Só o próprio interesse na solução de problemas pessoalmente vivenciados pode fomentar uma prática de um agir responsável, e esta prática do agir responsável no âmbito local, por sua vez, transforma os homens em cidadãos livres, dotados de consciência de responsabilidade, agora também em relação ao âmbito nacional (BOESCHE, 1987, p. 120).

Tocqueville aborda aqui um problema de grande importância para a sobrevivência das democracias contemporâneas. $\mathrm{O}$ crescente distanciamento entre governantes e governados esvazia a substância do processo democrático e o limita a um espetáculo eleitoral em que periodicamente, a cada

12 Nessa passagem Tocqueville antecipa os críticos contemporâneos da teoria elitista da democracia, os quais contestam a suposição de que o povo, por um lado, não estaria apto a avaliar programas e projetos políticos, mas, por outro lado, seria suficientemente capaz e maduro para escolher os seus governantes. Esta inconsistência da teoria competitiva e elitista foi também chamada de "dilema schumpeteriano" (Santoro, apud SCHMIDT, 1995, p. 137). 
quatro anos, poderosos grupos competem entre si pelos votos do eleitorado. Isso - quanto muito - obriga os governantes a um certo grau de responsiveness, a considerar os desejos, interesses, opiniões e humores presentes na população, ou melhor dizendo, no eleitorado, mas, sem dúvida nenhuma, de modo impróprio para criar possibilidades de um agir livre e auto-responsável. "Democratic freedom demands that one rely on oneself, one's effort, and one's neighbors in order to accomplish anything" (BOESCHE, 1987, p. 122).

Acontece que a maioria da população não se mostra interessada em conservar ou fomentar a liberdade. Suas ações na esfera pública são basicamente ditadas por seus interesses econômicos e privados. Surge o perigo da "invasão do irracional na política“ (HERETH, 1979, p. 35) e do desrespeito pelos direitos das minorias.

Por isso os cidadãos têm de ser educados e capacitados para estarem aptos a determinar sua própria sorte, a conduzir a política, a se valerem de sua razão e a controlar e dominar suas paixões. Não negligenciando a importância do sistema educacional e escolar e seus ensinamentos, Tocqueville avisa que só a experiência e o hábito podem fomentar um agir sensato, consciente e responsável. "Por isso mesmo, é na comuna que reside a força dos povos livres. As instituições comunais são para a liberdade aquilo que as escolas primárias são para a ciência; pois a colocam ao alcance do povo, fazendo-o gozar do seu uso pacífico e habituar-se a servir-se dela. Sem instituições comunais, pode uma nação dar-se um governo livre, mas não tem o espírito da liberdade" (TOCQUEVILLE, 1977, p. 54).

$\mathrm{O}$ cidadão que os tempos democráticos exige encontra na política comunal o campo de treinamento e da consolidação do que hoje se costuma chamar de "cidadania ativa" (BENEVIDES, 1991), que o prepara para tornar-se cidadão da república: "naquela esfera restrita que se acha ao seu alcance, procura governar a sociedade; habitua-se com as formas sem as quais a liberdade só procede por meio de revoluções, deixa-se penetrar pelo seu espírito, toma gosto pela ordem, compreende a harmonia dos poderes e por fim reúne idéias claras e práticas da natureza dos seus deveres assim como da extensão de seus direitos" (TOCQUEVILLE, 1977, p. 60).
Informações "teóricas" não farão de um habitante de uma comuna um cidadão, ciente de seus direitos, deveres, liberdades e possibilidades de ação. Todavia, só através da experimentação da liberdade política na prática e através da participação e do envolvimento ativo nos assuntos públicos o exercício da cidadania pode transformarse em elemento constitutivo dos hábitos e do modo de viver do cidadão.

Na comuna da Nova Inglaterra a identidade entre governantes e governados parecia aproximarse da soberania popular do contrato social de Rousseau: "Na comuna, como aliás em toda parte, o povo é a fonte dos poderes sociais; mas em nenhuma outra parte exerce o seu poder de maneira mais imediata. O povo, na América, é um senhor ao qual é preciso obedecer até os últimos limites do possível" (idem, p. 54ss).

Cabe frisar que, conforme as exigências rousseaunianas, na Nova Inglaterra "a lei da representação não é de modo algum admitida" (idem, p. 55); "o governo emana realmente dos governados" (idem, p. 59) na medida em que o corpo de eleitores dirige diretamente os seus magistrados, por meio das reuniões comunais (town meetings), de modo que "o princípio da soberania do povo paira sobre todo o sistema político dos angloamericanos" (idem, p. 56).

Para Tocqueville a realidade americana corresponde ao modelo de uma ordem política republicana, "que transforma os cidadãos, através da prática, em depositários da própria ordem" (HERETH, 1979, p. 40). Na medida em que o hábito, a experiência e os costumes promovem o amor pela liberdade prática, a participação nos assuntos públicos, que inicialmente se deveu sobretudo a cálculos de interesse e motivos de utilidade, ganha através da experiência cidadã do agir político uma qualidade própria, que se torna almejável por si mesma: "Não mais conveniências, mas o próprio agir político se torna razão da colaboração. A política e o agir político em comum une os cidadãos à comunidade" (ibidem).

Desse modo, o agir político corresponde a um campo próprio da atividade humana, transpondo a interpretação utilitarista da ordem política e do agir político, que restringe a política à perseguição de interesses econômicos e privados, à esfera da sociedade. 


\section{CONCLUSÃO}

Sendo a busca pela liberdade política a preocupação primordial no pensamento político de Alexis de Tocqueville, a sua concepção traz subsídios fundamentais para uma abordagem democratizante da descentralização político-administrativa, além de enriquecer os atuais debates teóricos e práticos - em torno das possibilidades de uma (re)vitalização das democracias contemporâneas. Como os atuais teóricos da democracia deliberativa ou dialógica (sobretudo HABERMAS, 1993; 1995), Tocqueville aposta no efeito conscientizador da prática política, no debate público de argumentos controversos como principal fonte de racionalização dos processos de tomada de decisão. No entanto, a abordagem de Tocqueville não tem como enfoque a situação comunicativa em si; ela enfatiza a dimensão histórica de uma possível transformação da sociedade em conseqüência de uma conscientização promovida por uma prática política constante nas arenas da política local e nas organizações da sociedade civil. Dando prioridade a mudanças de consciência e de valores, mostrando-se cético em relação a estratégias institucionalistas, Tocqueville também traz uma contribuição significativa para o comunitarismo, que, por sua vez, põe esperanças na transformação do sistema de valores da sociedade, no fortalecimento do engajamento cidadão e em uma alteração geral do "clima moral" (ETZIONI, 1995, p. 101).

Finalmente, e na medida em que Tocqueville frisa o potencial inerente à democracia local de promover uma mudança de consciência e uma valorização do bem comum no processo político, sua obra traz importantes subsídios para as atuais concepções teóricas que buscam conciliar a teoria política da democracia com as teorias do desenvolvimento sustentável que partem da necessidade da superação do atual modo de desenvolvimento social e ecologicamente insustentável - que, por sua vez, é considerado conseqüência de uma visão utilitarista da política que reduz a política à perseguição de interesses econômicos e privados. Concordando com boa parte das concepções que propõem uma democracia ecológica ou ambiental ${ }^{13}$, Tocqueville considera a democratização das instituições básicas da sociedade uma prática permanente de participação política, assim como a conseqüente promoção de uma identidade coletiva como fatores imprescindíveis para a promoção do bem comum nas sociedades democráticas. Contudo, os mesmos temores e preocupações que outrora afligiram o restless mind (LAWLER, 1993) de Tocqueville são os temas e preocupações centrais na teoria democrática contemporânea, evidenciando com isso a atualidade do pensamento tocquevilleano para nossos tempos.

Recebido para publicação em 1 de novembro de 2000.

\footnotetext{
13 Ver, por exemplo, Mason (1999, p. 31-46), que discute as concepções sobre democracia e meio ambiente em diversas ideologias políticas, como o conservadorismo, o neoliberalismo, o liberalismo de bem-estar, o ecocentrismo, a ecologia social e o eco-socialismo.
}

Klaus Frey (frey@tecpar.br) é Mestre em Ciência da Administração e Doutor em Ciências Sociais pela Universidade de Konstanz, Alemanha. Atualmente é Professor da Pontifícia Universidade Católica do Paraná (PUC-PR).

\section{REFERÊNCIAS BIBLIOGRÁFICAS}

ALULIS, J. 1998. The Price of Freedom : Tocqueville, the Farmers, and the Antifederalists. Perspectives on Political Science, v. 27, n. 2, p. 85-91.

ARENDT, H. 1997. Entre o passado e o futuro. $4^{\mathrm{a}}$ ed. São Paulo : Perspectiva

ARISTÓTELES. 1997. Politica. $3^{\mathrm{a}}$ ed. Brasília : Edunb.
ARON, R. 1993. As etapas do pensamento sociológico. $4^{\mathrm{a}}$ ed. São Paulo : Martins Fontes.

BENEVIDES, M. V. M. 1991. A cidadania ativa : referendo, plebiscito e iniciativa popular. São Paulo : Ática.

BOESCHE, R. 1987. The Strange Liberalism of Alexis de Tocqueville. Ithaca: Cornell University Press. 
BORON, A. A. 1994. Alexis de Tocqueville, a democracia e o estatismo da sociedade burguesa. In : Estado, capitalismo e democracia na América Latina. Rio de Janeiro : Paz e Terra.

COMMAGER, H. S. 1993. Commager on Tocqueville. Columbia : University of Missouri Press.

DIGGENS, J. P. 1999. Max Weber : a política e o espírito da tragédia. Rio de Janeiro : Record.

DÖHN, L. 1998. Liberalismus Spannungsverhältnis von Freiheit, Gleichheit und Eigentum. In : NEUMANN, F. (org.). Handbuch Politische Theorien und Ideologien. Vol.1, 2 ${ }^{\text {a }}$ ed. Opladen : Leske + Budrich.

ETZIONI, A. 1995. Too Many Rights, Too Few Responsabilities. In : Walzer, M. (org.). Toward a global civil society. The Friedrich Ebert Stiftung Series on International Political Currents. Providence/Oxford (UK) : Berghahn.

HABERMAS, J. 1962. Strukturwandel der Öffentlichkeit : Untersuchungen zu einer Kategorie der bürgerlichen Gesellschaft. Darmstadt/Neuwied : Luchterhand.

. 1993. Faktizität und Geltung. Beiträge zur Diskurstheorie des Rechts und des demokratischen Rechtsstaats. $3^{\text {a }}$ ed. Frankfurt am Main : Suhrkamp.

1995. Três modelos de democracia. Lua Nova, São Paulo, n. 36, p. 39-53.

HERETH, M. 1979. Alexis de Tocqueville : zur Gefährdung der Freiheit in der Demokratie. Stuttgart : Kohlhammer.

JASMIN, M. G. 1997a. Alexis de Tocqueville. A historiografia como ciência da política. Rio de Janeiro : Access.

1997b. Tocqueville, a providência e a história. Dados, Rio de Janeiro, v. 40, n. 2, p. 199-228.

LAWLER, P. 1993. The Restless Mind: Alexis de Tocqueville on the Origin and Perpetuation of Human Liberty. Lanham : Rowman \& Littlefield.
MANENT, P. 1998. Democratic Man, Aristocratic Man, and Man Simply : Some Remarks on an Equivocation in Tocqueville's Thought. Perspectives on Political Science, v. 27, n. 2, p. $79-84$.

MASON, M. 1999. Environmental Democracy. London : Earthscan.

NUNES, E. 1996. Poder local, descentralização e democratização : um encontro difícil. São Paulo em perspectiva, v. 10, n. 3, p. 32-39.

OLDFIELD, A. 1990. Citizenship and Community : Civic Republicanism and the Modern World. London : Routledge.

QUIRINO, C. G. 1998. Tocqueville : a realidade da democracia e a liberdade ideal. In : et alii (orgs.). Clássicos do pensamento político. São Paulo : Edusp.

RODRÍGUEZ, R. V. 1998. A democracia liberal segundo Alexis de Tocqueville. São Paulo : Mandarim.

ROUSSEAU, J.-J. 1973. Do contrato social : ou princípios do direito político. São Paulo : Abril. Coleção Os pensadores, v. XXIV.

TOCQUEVILLE, A. 1977. A democracia na América. Belo Horizonte : Itatiaia.

1982. O antigo regime e a revolução. $2^{\mathrm{a}}$ ed. Brasília : Edunb.

SCHMIDT, M. G. 1995. Demokratietheorien Eine Einführung. Opladen : Leske + Budrich.

SOUZA, F. P. 1988. A Revolução Francesa e o pensamento político de Jean-Jacques Rousseau. Reflexão, n. 42 , p. 58-80.

VIANNA, L. W. 1993. Lições da América : o problema do americanismo em Tocqueville. Lua Nova, São Paulo, n. 30, p. 159-193.

WASCHKUHN, A. 1998. Demokratietheorien : Politiktheoretische und ideengeschichtliche Grundzüge. München/Wien : R. Oldenbourg.

ZETTERBAUM, M. 1967. Tocqueville and the Problem of Democracy. Stanford, California : Stanford University Press. 